\title{
USULAN PENERAPAN TOTAL PRODUCTIVE MAINTENANCE DI PT SHINKOBE ENGINEERING PADA MESIN CNC HORIZONTAL MAHO (MH-C 700)
}

\author{
Hana Silvia Dwi Putri ${ }^{1}$, Sofiyan Anwar ${ }^{2}$ \\ ${ }^{1}$ Program Studi Teknik Industri / Politeknik META Industri Cikarang / \\ hanasilvia22@politeknikmeta.ac.id \\ ${ }^{2}$ Program Studi Teknik Industri / Politeknik META Industri Cikarang / \\ sofyan.anewar98@gmail.com
}

\begin{abstract}
Care is part of the company's business processes and plays an important role in the success of an organization. In maintaining quality and increasing productivity, one important factor that must be considered is the issue of machine maintenance and production facilities. The frequent damage to machinery and equipment causes the OEE (overall equipment effectiveness) to be low so that the effectiveness in the use of machinery and equipment is low. This happened to pt. Shinkobe engineering.

PT. Shinkobe engineering has an oee value on one of its machines, namely the cnc milling horizontal-maho MH-C 700 which has an oee value that is still below the standard according to the japan institute of plant maintenance (JIPM) which is $85 \%-95 \%$. In this case, the implementation of preventive maintenance at PT. Shinkobe engineering is not yet optimal because machines still often experience corrective maintenance improvements. So the researchers proposed the application of total productive maintenance on the horizontal millingmaho cnc machine ( $\mathrm{MH}-\mathrm{C}$ 700)

The method used for the calculation of OEE with a problem-solving tool is using a fishbone diagram. With the aim that is to find out the cause of the frequent occurrence of the machine stops operating in a short and long time and to find out the cause of the low oee presentation on cnc horizontal milling - maho machines ( $M H-C 700)$.

So from the results of the study the OEE values were $52 \%$ and $65 \%$. From the research results it is known that the cause of the low percentage of oee on cnc horizontal milling - maho machines $(\mathrm{MH}-\mathrm{C} 700)$ is a machine that is sometimes damaged when in use and the actual cycle time is far different from the time it should be set, because frequent tools are broken so that time the actual cycle of the timeline is not ideal. As for the causes of the frequent occurrence of the machine stops operating in a short time and a long time that is irregular maintenance activity even though it has been scheduled, tools are often damaged so it must be sharpened first, resetting the tools on the work table that causes the machine to stop short and there is a waiting time when the tools are sharpened/waiting for the tools to be used
\end{abstract}

keywords: maintenance, overall equipment effeciveness, total productive maintenance.

\begin{abstract}
ABSTRAK
Perawatan merupakan bagian dari proses bisnis perusahaan dan memainkan peran penting dalam keberhasilan suatu organisasi. Dalam mempertahankan mutu dan meningkatkan produktivitas, salah satu faktor penting yang harus diperhatikan adalah masalah perawatan mesin (maintenance) dan fasilitas produksi. Dari sering rusaknya mesin dan peralatan menyebabkan nilai OEE (Overall Equipment Effectiveness) menjadi rendah seingga keefektifan dalam penggunaan mesin dan peralatan menjadi rendah. Hal ini terjadi pada PT. Shinkobe Engineering.
\end{abstract}


PT. Shinkobe Engineering memiliki nilai OEE pada salah satu mesinnya yaitu mesin CNC Milling Horizontal-Maho MH-C 700 yang memiliki nilai OEE yang masih di bawah standar menurut Japan Institute of Plant Maintenance (JIPM) yaitu 85\%-95\%. Dalam hal ini, implementasi preventive maintenance di PT. Shinkobe Engineering belum optimal karena mesin-mesin masih sering mengalami perbaikan corrective maintenance. Sehingga peneliti mengusulkan penerapan Total Productive Maintenance pada mesin CNC Horizontal MillingMaho (MH-C 700).

Adapun metode yang digunakan perhitungan OEE dengan alat pemecah permasalahan menggunakan diagram Fishbone. Dengan Tujuan yaitu untuk mengetahui penyebab sering terjadinya mesin berhenti beroperasi dalam waktu singkat dan lama dan mengetahui penyebab rendahnya presentasi OEE pada mesin CNC Horizontal Milling - Maho (MH-C 700).

Maka dari hasil penelitian didaptkan nilai OEE sebesar 52\% dan $65 \%$. Dari hasil penelitian diketahui penyebab rendahnya presentase OEE pada mesin CNC Horizontal Milling - Maho (MH-C 700) adalah mesin yang terkadang rusak saat sedang digunakan dan waktu actual cycle time yang jauh berbeda dari waktu yang seharusnya ditetapkan, karena sering terjadinya tools rusak sehingga waktu actual cycle timenya menjadi tidak ideal. Adapun penyebab penyebab sering terjadinya mesin berhenti beroperasi dalam waktu singkat dan lama yaitu Kegiatan perawatan tidak teratur walau sudah dijadwalkan, Tools sering rusak sehingga harus diasah dahulu, penyetingan ulang tools diatas meja kerja yang menyebabkan mesin berhenti singkat dan ada waktu tunggu ketika tools sedang diasah/menunggu giliran tools dipakai.

Kata Kunci : Perawatan, Overall Equipment Effeciveness, Total Productive Maintenance.

\section{PENDAHULUAN}

Perawatan merupakan bagian dari proses bisnis perusahaan dan memainkan peran penting dalam keberhasilan suatu organisasi. Dalam mempertahankan mutu dan meningkatkan produktivitas, salah satu faktor penting yang harus diperhatikan adalah masalah perawatan mesin (maintenance) dan fasilitas produksi. Berkaitan dengan hal tersebut, maka pihak yang menangani masalah perawatan harus mampu menemukan sistem perawatan yang paling baik untuk dapat meminimasi jumlah Breakdown mesin dan biaya perbaikan atau perawatan mesin yang dikeluarkan menurut Pujotomo dan Rama (2007). Selain kerugian finansial, terjadinya kerusakan juga dapat mengancam keselamatan para pekerja menurut Pranoto et al (2013).

PT. Shinkobe Enginering merupakan perusahaan yang menerima pekerjaan dari perusahaan lain atau biasa disebut job order. Salah satu produk yang diproduksi yaitu sprue bush. Sprue bush yaitu bagian dari mold base yang berfungsi untuk mengalirkan cairan ke inti cetakan. Proses produksinya salah satunya menggunakan mesin CNC Milling Horizontal-Maho MH-C 700.

Dalam hal ini, implementasi preventive maintenance di PT. Shinkobe Engineering belum optimal karena mesin-mesin masih sering mengalami perbaikan corrective maintenance. Mesin sering mengalami corrective maintenance sehingga mesin harus diberhentikan hingga perbaikan selesai. Tindakan ini menyebabkan peningkatan biaya produksi karena perbaikan dilakukan ketika produksi berjalan, sehingga membuang waktu produksi dan biasanya perbaikan mesin tersebut memakan waktu yang lama karena spare part susah untuk dicari sehingga loading pekerjaan di mesin itu menumpuk.

Untuk mengatasi hal tersebut maka penelitian ini mencoba untuk mengusulkan penerapan Total Productive Maintenance pada mesin CNC Horizontal Milling-Maho (MH-C 700).

\section{METODE PENELITIAN}

Penelitian ini dilakukan dengan beberapa tahapan meliputi Studi Penelitian, Identifikasi masalah, Studi literatur, Perumusan masalah, Pengumpulan data, pengolahan data sampai dengan usulan penerapan TPM. 
Data yang dikumpulan dalam penelitian ini adalah lama waktu mesin beroprasi, waktu siklus, downtime, waktu operasi, produk cacat, jumlah mesin berapa kali breakdown dan total produk yang diproduksi selama bulan 1 Maret- 24 April 2019.

Kemudian pengolahan data dilakukan dengan beberapa perhitungan yaitu :

1. Perhitungan Availability

Dalam perhitungan availability akan diketahui berapa lama mesin bekerja dalam proses produksi.

2. Perhitungan Performance Efficiency

Perhitungan Performance Efficiency berfungsi untuk mengetahui seberapa baik performansi mesin ketika bekerja.

3. Perhitungan Quality Rate

4. Perhitungan Quality Rate merupakan suatu rasio yang menggambarkan kemampuan peralatan dalam menghasilkan produk yang sesuai dengan standar.

5. Perhitungan Overall Equipment Effectiveness

Setelah mendapatkan nilai availability, performance efficiency dan quality rate, langkah selanjutnya adalah menghitung Overall Equipment Effectiveness (OEE) dengan cara mengalikan ketiga aspek tersebut dan kemudianmembandingkan dengan nilai OEE standart dunia yaitu $85 \%$.

6. Perhitungan Six Big Losses

Setelah OEE dihitung, dicari faktor utama yang menyebabkan kegagalan dengan perhitungan six big losses. Six big losses berguna untuk bisa mengetahui faktor yang paling berppengaruh dalam breakdown nya mesin mesin CNC Horizontal Milling-Maho (MH-C 700).

\section{HASIL DAN PEMBAHASAN}

\subsection{Perhitungan OEE (Overall Equipment Effectiveness)}

Overall Equipment Effectiveness (OEE) adalah suatu metode pengukuran tingkat efektifitas pemakaian suatu peralatan atau sistem dengan mengikutsertakan beberapa sudut pandang dalam proses perhitungan tersebut. Sudut pandang yang diikutsertakan dalam perhitungan antara lain adalah availability rate, performance rate, dan quality rate, dari suatu mesin atau sistem. Langkah- langkah perhitungan nilai OEE adalah sebagai berikut :

\section{- Availability rate}

Availability merupakan tingkat ketersediaan suatu mesin untuk dapat menghasilkan output. Perhitungan availability sebagai berikut :

$$
\text { Availability rate }=\frac{\text { Operating Time }}{\text { Loading Time }} \times 100 \%
$$

Berikut tabel 1. perhitungan Availability rate perhari bulan Maret dan April 2019.

Tabel 1. Availability rate bulan Maret - 24 April 2019

\begin{tabular}{|c|c|c|c|c|}
\hline Bulan & $\begin{array}{c}\text { Loading Time } \\
\text { (Menit) }\end{array}$ & $\begin{array}{c}\text { Down Time } \\
\text { (Menit) }\end{array}$ & $\begin{array}{c}\text { Operating Time } \\
\text { (Menit) }\end{array}$ & $\begin{array}{c}\text { Availability } \\
\text { rate }\end{array}$ \\
\hline Maret & 2945 & 450 & 2495 & $85 \%$ \\
\hline April & 2555 & 525 & 2030 & $79 \%$ \\
\hline
\end{tabular}


- Performance rate

Perfromance Rate adalah rasio yang menunjukan kemampuan peralatan dalam menghasilkan barang. rumus yang digunakan untuk mencari Perfromance Ratio adalah:

$$
\text { Perfomance Rate }=\frac{\text { Output } x \text { ideal cycle time }}{\text { Operating Time }} \times 100 \%
$$

Perhitungan nilai performance rate per bulan pada mesin CNC Horizontal Milling-Maho (MHC 700) pada bulan Maret-24 April 2019 dapat dilihat pada tabel 2.

Tabel 2. Perfomance Rate Bulan Maret - 24 April 2019

\begin{tabular}{|c|c|c|c|c|}
\hline Bulan & $\begin{array}{c}\text { Ideal Cycle Time } \\
\text { (menit) }\end{array}$ & $\begin{array}{c}\text { Output } \\
\text { Produk }\end{array}$ & $\begin{array}{c}\text { Operating Time } \\
\text { (menit) }\end{array}$ & $\begin{array}{c}\text { Perfomance } \\
\text { Rate }\end{array}$ \\
\hline Maret & 139 & 12 & 2495 & $67 \%$ \\
\hline April & 139 & 12 & 2030 & $82 \%$ \\
\hline
\end{tabular}

- $\quad$ Quality Rate

Quality Rate adalah ratio yang menunjukan kemampuan peralatan dalam menghasilkan produk yang sesuai dengan standart. rumus yang digunakan untuk mencari Quality Rate adalah:

$$
\text { Quality Rate }=\frac{\text { Jumlah Output }- \text { Produksi Cacat }}{\text { Jumlah Output }} \times 100 \%
$$

Adapun Perhitungan nilai Quality Rate per bulan pada mesin CNC Horizontal Milling-Maho (MH-C 700) pada bulan Maret-24 April 2019 dapat dilihat pada tabel 3.

Tabel 3. Quality Rate bulan Maret - 24 April 2019

\begin{tabular}{|l|l|l|l|l|}
\hline Bulan & $\begin{array}{l}\text { Total } \\
\text { Produksi }\end{array}$ & $\begin{array}{l}\text { Output } \\
\text { Produk }\end{array}$ & Defect & Quality Rate \\
\hline Maret & 13 & 12 & 1 & $92 \%$ \\
\hline April & 12 & 12 & 0 & $100 \%$ \\
\hline
\end{tabular}

- Pengukuran Nilai OEE (Overall Equipment Effectiveness)

Setelah nilai Availability rate, Performance Rate, Quality Rate didapatkan, maka selanjutnya menghitung nilai OEE, dan rumus yang digunakan untuk pengukuran OEE. Berikut di bawah ini merupakan perhitungan nilai OEE bulan Maret dan April 2019.

OEE $=$ Availability rate $x$ performance $x$ Quality

Di bawah ini merupakan Tabel 4. hasil perhitungan tiga komponen OEE.

Tabel 4. Perhitungan tiga komponen OEE

\begin{tabular}{|c|c|c|c|}
\hline Bulan & $\begin{array}{c}\text { Availability rate } \\
\text { rate }\end{array}$ & Perfomance Rate & Quality Rate \\
\hline Maret & $85 \%$ & $67 \%$ & $92 \%$ \\
\hline April & $79 \%$ & $82 \%$ & $100 \%$ \\
\hline
\end{tabular}

OEE Maret $=(85 \%$ × $67 \%$ × 95\% $)=52 \%$

OEE April $\quad=(79 \% \times 82 \% \times 100 \%)=65 \%$

Perhitungan nilai OEE per bulan pada mesin CNC Horizontal Milling-Maho (MH-C 700) pada bulan Maret-24 April 2019 dapat dilihat pada tabel 5.

Tabel 5. OEE bulan Maret -24 april 2019

\begin{tabular}{|c|c|c|c|c|}
\hline Bulan & $\begin{array}{c}\text { Availability rate } \\
\text { rate }\end{array}$ & Perfomance Rate & Quality Rate & OEE \\
\hline Maret & $85 \%$ & $67 \%$ & $92 \%$ & $52 \%$ \\
\hline April & $79 \%$ & $82 \%$ & $100 \%$ & $65 \%$ \\
\hline
\end{tabular}


- $\quad$ Perhitungan Six big losses

Pengukuran six big losess ini untuk mengidentifikasi kerugian seperti berhentinya mesin atau peralatan, kerugian persiapan atau penyetelan sebelum melakukan proses produksi, kerugian kerusakan produk serta tersembunyi seperti pengurangan kecepatan serta kerugian idle and minnor stopages. Perhitungan Six Big Losses meliputi Equipment Failure Losses (Breakdowns), Setup Adjustment Losses, Idling and Minor Stoppages Losses, Reduced Speed Losses, Defect Losses dan Reduces Yield.

- $\quad$ Equipment failure losses

$$
\text { Equipment Failure losses }=\frac{\text { Downtime }}{\text { Loading Time }} \times 100 \%
$$

Untuk Perhitungan nilai Equipment Failure losses per bulan pada mesin CNC Horizontal Milling-Maho (MH-C 700) pada bulan Maret-24 April 2019 dapat dilihat pada Tabel 6.

Tabel 6. Breakdown Losses bulan Maret - 24 April 2019

\begin{tabular}{|c|c|c|c|}
\hline Bulan & $\begin{array}{c}\text { Downtime } \\
\text { (menit) }\end{array}$ & $\begin{array}{c}\text { Loading Time } \\
\text { (menit) }\end{array}$ & Breakdown Losses \\
\hline Maret & 450 & 2945 & $15 \%$ \\
\hline April & 525 & 2555 & $21 \%$ \\
\hline
\end{tabular}

- $\quad$ Setup adjustment losses

$$
\text { Setup adjusment losses }=\frac{\text { Set up Time }}{\text { Loading Time }} \times 100 \%
$$

Untuk Perhitungan nilai set up and adjustment losses per bulan pada mesin CNC Horizontal Milling-Maho (MH-C 700) pada bulan Maret-24 April 2019 dapat dilihat pada Tabel 7.

Tabel 7. Set up adjustment losses bulan Maret - 24 April 2019

\begin{tabular}{|c|c|c|c|c|}
\hline Bulan & $\begin{array}{c}\text { Total } \\
\text { Output }\end{array}$ & $\begin{array}{c}\text { Set Up } \\
\text { (menit) }\end{array}$ & $\begin{array}{c}\text { Loading Time } \\
\text { (menit) }\end{array}$ & Set Up Losses \\
\hline Maret & 13 Prouk & 195 & 2945 & $7 \%$ \\
\hline April & 12 Produk & 180 & 2555 & $7 \%$ \\
\hline
\end{tabular}

- $\quad$ Idling minor Stoppages Losses

$$
\text { lling and minor stoppages losses }=\frac{(\text { target-Output }) X \text { ideal cycle time }}{\text { Loading Time }} \times 100 \%
$$

Perhitungan nilai Idle and Minor Stoppages per bulan pada mesin CNC Horizontal Milling-Maho (MH-C 700) pada bulan Maret-24 April 2019 dapat dilihat pada Tabel 8.

Tabel 8. nilai Idle and Minor Stoppages bulan Maret-24 April 2019

\begin{tabular}{|c|c|c|c|}
\hline Bulan & $\begin{array}{c}\text { Target } \\
\text { (Produk) }\end{array}$ & $\begin{array}{c}\text { Output } \\
\text { (produk) }\end{array}$ & $\begin{array}{c}\text { Idling and minor } \\
\text { Stoppages }\end{array}$ \\
\hline Maret & 18 & 12 & $28 \%$ \\
\hline April & 15 & 12 & $16 \%$ \\
\hline
\end{tabular}


- $\quad$ Reduced Speed Losses

$$
\text { Reduced Speed Losses }=\frac{\text { (actual cycle time-ideal cycle time }) \times \text { Output }}{\text { Loading Time }} \times 100 \%
$$

Perhitungan nilai Reduced Speed Losses per bulan pada mesin CNC Horizontal MillingMaho (MH-C 700) pada bulan Maret-24 April 2019 dapat dilihat pada tabel 9.

Tabel 9. Reduced Speed Losses bulan Maret - 24 April 2019

\begin{tabular}{|c|c|c|c|c|c|}
\hline Bulan & $\begin{array}{c}\text { Ideal Cycle } \\
\text { Time } \\
\text { (menit) }\end{array}$ & $\begin{array}{c}\text { Actual Cycle } \\
\text { Time } \\
\text { (menit) }\end{array}$ & $\begin{array}{c}\text { Loading } \\
\text { Time } \\
\text { (menit) }\end{array}$ & $\begin{array}{c}\text { Total } \\
\text { Produk }\end{array}$ & $\begin{array}{c}\text { Reduced } \\
\text { Speed } \\
\text { Losses }\end{array}$ \\
\hline Maret & 139 & 208 & 2945 & 12 & $28 \%$ \\
\hline April & 139 & 169 & 2555 & 12 & $14 \%$ \\
\hline
\end{tabular}

- $\quad$ Defects Losess

$$
\text { Defect Losses }=\frac{\text { ideal cycle time } x \text { total defect }}{\text { Loading Time }} \times 100 \%
$$

Perhitungan nilai Quality losses per bulan pada mesin CNC Horizontal Milling-Maho (MH-C 700) pada bulan Maret-24 April 2019 dapat dilihat pada tabel 10.

Tabel 10. Quality losses bulan Maret-24 April 2019

\begin{tabular}{|c|c|c|c|c|c|c|}
\hline Bulan & $\begin{array}{c}\text { Total } \\
\text { Produksi }\end{array}$ & $\begin{array}{c}\text { Output } \\
\text { Ok }\end{array}$ & $\begin{array}{c}\text { Loading } \\
\text { Time } \\
\text { (menit) }\end{array}$ & $\begin{array}{c}\text { Ideal Cycle } \\
\text { Time } \\
\text { (menit) }\end{array}$ & $\begin{array}{c}\text { Total } \\
\text { Defect }\end{array}$ & $\begin{array}{c}\text { Defect } \\
\text { Losses }\end{array}$ \\
\hline Maret & 13 & 12 & 2945 & 139 & 1 & $5 \%$ \\
\hline April & 12 & 12 & 2555 & 139 & 0 & 0 \\
\hline
\end{tabular}

- $\quad$ Reduced Yield

$$
\text { Scrap losses }=\frac{\text { ideal cycle time } x \text { scrap }}{\text { Loading Time }} \times 100 \%
$$

Setelah melakukan perhitungan six big losses maka diketahuai mana losses yang terbesar sampai yang terkecil. Losses terbesar pada sampai terkecil pada mesin CNC Horizontal Milling-Maho (MH-C 700) yaitu, idle minor stoppages losses $28 \%$ dan 16\%, Reduced Speed Losses 28\% dan 14\%, equipment failure losses/Breakdown losses $15 \%$ dan 21\%, set up and adjustment losses 7\% dan 7\%, serta yang terkecil adalah Defect Losses 5\% dan $0 \%$. Untuk mempermudah dalam pembacaan hasil perhitungan six big losses maka ditampilkan gambar 1. hasil perhitungan analisis six big losses total pada bulan Maret 24 April 2019.

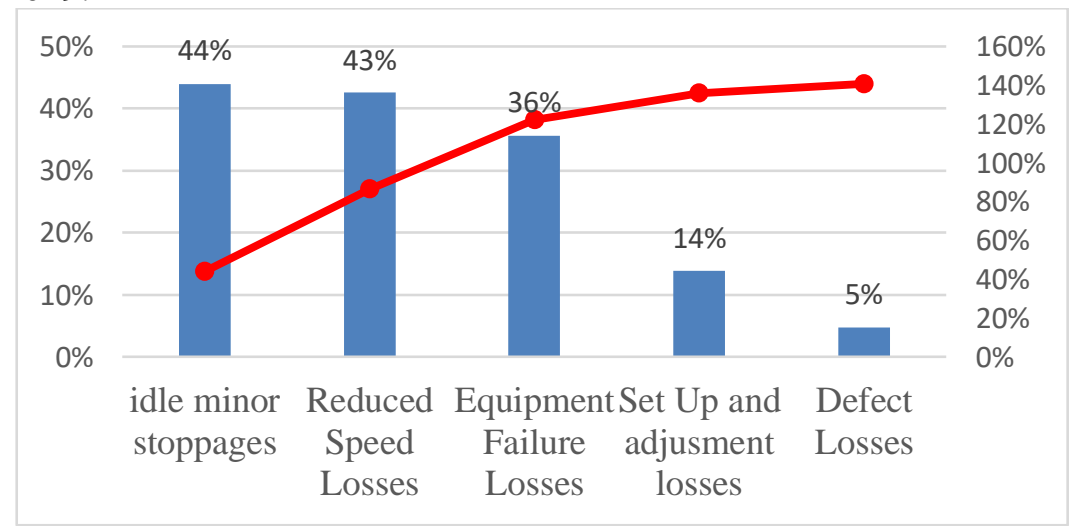

Gambar 1. six big losses pada bulan Maret - 24 April 2019. 


\subsection{Analisis Penyebab Rendahnya OEE}

Setelah dilakukan perhitungan six big losess pada mesin CNC Horizontal Milling-Maho (MH-C 700) dan dilakukan branstroming terhadap orang-orang yang terlibat langsung pada penelitian ini, yaitu operator mesin CNC Horizontal Milling-Maho (MH-C 700), maintenance serta supervisor produksi. Dari perhitungan diatas mengenai six big losses diketahui bahwa losses terbesar adalah pada idling minor stoppages losses yang memiliki presentase sebesar $28 \%$ dan 16\% pada bulan Maret dan April 2019. Kemudian untuk mengetahui akar penyebabnya dengan menggunakan Fishbone diagram, faktor yang dianalisa dalam Fishbone diagram adalah manusia, mesin, metode, dan material. Berikut dibawah ini gambar 2. diagram Fishbone tentang analisis idling minor stoppages losses.

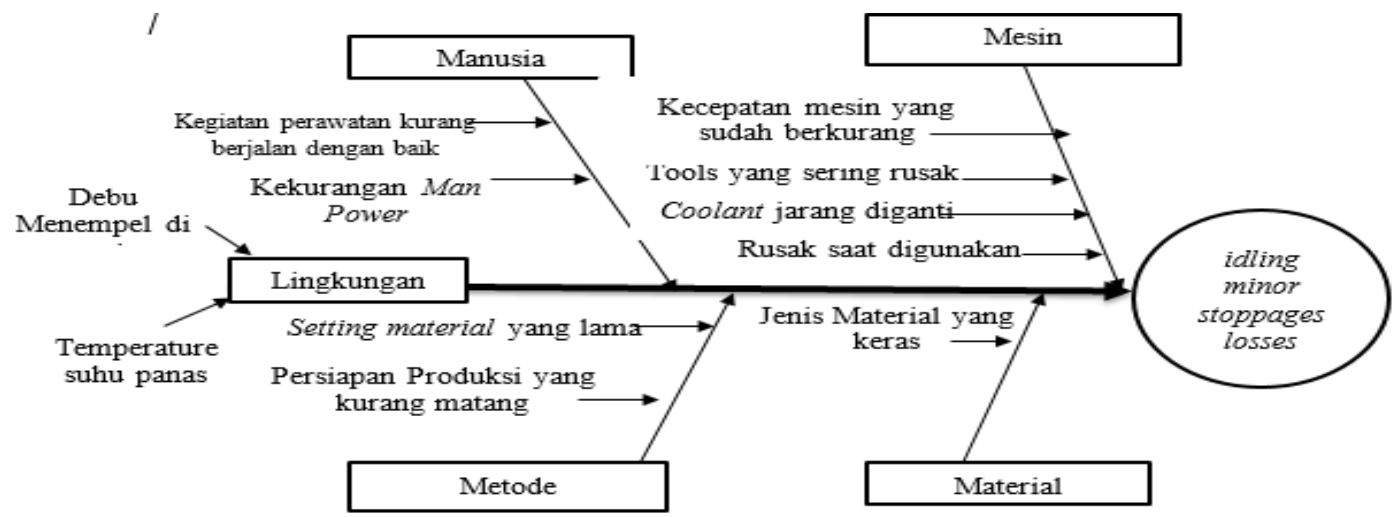

Gambar 2. Diagram Fishbone

Dengan penjelasan diagram Fishbone yang ditampilkan pada gambar 4.3 dapat diketahui apa penyebab rendahnya hasil nilai OEE yang akan dijelaskan pada penjelasan dibawah ini :

1. Manusia

Banyak faktor yang mempengaruhi kenapa Maintenance di PT. Shinkobe Engineering dikatakan belum baik karena pelaksanaan kegiatan perawatan terhadap mesin tidak berjalan dengan semestinya sesuai jadwal perawatan, sehingga mesin mengalami kerusakan sebelum tiba waktunya untuk perawatan. Hal ini juga tidak terlaksana karena pada bagaian maintenance yang masih kekurangan tenaga kerja pada bagian maintenance yang mana hanya ada 2 (dua) orang tenaga kerja dibagian maintenance yang harus terus rutin mengecek kondisi mesin yang tidak sedikit di PT Shinkobe Engineering karena hal ini menyebabkan tidak bisa melaksanakan perawatan secara lebih baik. Pengajuan penambahan tenaga kerja pada bagian maintenance sudah pernah diajukan namun top management menolaknya dengan alasan hanya akan menambah biaya saja. Jika penambahan tenaga kerja disetujui maka kegiatan perawatan bisa lebih teratur lagi dan mesin bisa dioperasikan dengan lebih maksimal lagi dan kerusakan mesin yang parah bisa dihindari dengan rutinnya pelaksanaan perawatan mesin.

2. Mesin

Kerugian yang disebabkan karena kerusakan peralatan dan mesin ini disebabkan karena tools untuk melakukan proses kerja sering rusak/aus hal ini dikarenakaan tools tersebut sering bergantian penggunaanya dengan mesin lain sehingga rentan sekali terhadap aus, dan juga karena jumlahnya terbatas sehingga mesin harus berhenti atau tidak dioperasikan. Kendala pada mesin itu yaitu kecepatan pengoprasian mesin yang sudah berkurang karena umur mesin dan juga metode perawatan yang kurang tepat sehingga kadang mesin sering mengalami kerusakan 
dan salah satu contohnya meja mesin yang bergetar atau kendor sehingga proses produksi kurang maksimal sehingga bisa menyebabkan hasil produksi kurang maksimal dan bisa menyebabkan NG (not good) pada produk. Hal ini terjadi karena tidak berjalannya perawatan terhadap mesin secara teratur dan hanya melakukan perbaikan jika mesin mengalami kerusakan saja, dan operator kurang tanggap mengenai gejala kerusakan mesin yang terjadi dan baru menyadari jika gejala sudah semakin parah. Dan masalah yang lain adalah penggantian collant untuk proses pendinginan saat sedang menjalankan mesin tidak dilakukan secara teratur dan hanya mengganti jika collant sudah sangat berbau yang tentunya membutuhkan waktu lebih karena harus menguras collant sampai habis, jika hal ini dibiarkan saja maka proses produksi bisa terganggu dan bisa menyebabkan hasil produksi kurang maksimal. Untuk mengantisipassi tools sering rusak lebih baik setiap mesin diberikan tools masing-masing yang sering digunakan dan mencari tools man untuk mengasah tools sehingga tools akan siap selalu digunakan.

\section{Metode}

Kerugian ini mengakibatkan waktu actual cycle time tidak sesuai dengan standar cycle time yang sudah ditetapkan oleh perusahaan. Dalam kerugian ini penyebab utamanya adalah penyetingan material dan tools yang memakan waktu yang lama yang membtuhkan waktu sekiranya 15 menit untuk menyeting material di atas mesin dan karena tools yang rusak/aus sehingga harus diasah atau diganti dengan yang baru dan harus melakukan kembali penyetingan ulang tools pada benda kerja yang menyebabkan actual cycle time tidak sesuai dengan semestinya, untuk mengantisipasi hal tersebut sebaiknya dibuatkan alat bantu setting material sehingga bisa mempercepat prosess karena mesin itu hanya memproses produk itu saja.

\section{Material}

Masalah yang terjadi adalah material yang sifatnya keras dan ulet namun kemampuan mesin kurang maksimal dalam pengerjaannya serta tools yang sering aus karena penggunaanya sering bergantian.

\section{Lingkungan}

Masalah yang terjadi pada lingkungan yaitu sering terjadinya penumpukan debu dan kotoran pada mesin dan juga panel sehingga bisa menyebabkan masalah jika tidak dibersihkan, dan juga suhu ruangan yang dirasa cukup panas sehingga membuat para operator mesin merasa cepat kelelahan karena suhu yang diatas rata-rata.

\section{KESIMPULAN}

Penyebab rendahnya presentase OEE pada mesin CNC Horizontal Milling - Maho (MH-C 700) adalah dari nilai Availability rate yang tergolong lumayan rendah, yang disebabkan oleh mesin yang terkadang rusak saat sedang digunakan dan kerusakan pada tools. Adapun dari nilai Perfomance Rate merupakan presentase yang terendah dari ketiga komponen dari OEE. Yang menyebabkan nilai presentase rendah adalah waktu actual cycle time yang jauh berbeda dari waktu yang seharusnya ditetapkan, karena sering terjadinya tools rusak sehingga waktu actual cycle timenya menjadi tidak ideal lagi.

Penyebab sering terjadinya kerusakan mesin yang menyebabkan mesin berhenti beroperasi dalam waktu yang lama dan singkat yaitu kegiatan perawatan tidak teratur walau sudah dijadwalkan, tools sering rusak sehingga harus diasah dahulu, penyetingan ulang tools diatas meja kerja yang menyebabkan mesin berhenti singkat dan ada waktu tunggu ketika tools sedang diasah/menunggu giliran tools dipakai.

\section{DAFTAR PUSTAKA}

Almeanazel, O.T.R. 2010, "Total Productive Maintenance Review and Overall Equipment Effectiveness" Vol. 4, No. 4 ISSN 1995-6665, Departement Of Mechanichal and Industrial Engineering, Hashemite University, Zarqa, Jordan.

Ansori dan Mustajib. 2013. Sistem perawatan terpadu. Yogyakarta. Graha Ilmu. 
Arifianto, Asyrof. 2018. "Penerapan Total Productive Maintenance (TPM) Dengan Menggunakan Metode Overall Equipment Effectiveness". Tugas Akhir. Fakultas Teknologi Industri Yogyakarta. Universitas Islam Indonesi. Yogyakarta.

Corder, A., 1996. Teknik Manajemen Pemeliharaan. Erlangga. Jakarta.

Ganjar Subagio, Dalmasius. 2012. Pemograman CNC dan Aplikasi di Dunia Industri. Informatika Bandung.

Pranoto, J., et. al. 2013. Implementasi Studi Preventive Maintenance Fasilitas Produksi dengan Metode Reliability Centered maintenance pada PT. XYZ. E-jurnal Teknik Industri FT USU Vol 1: 18 - 24

Pujotomo dan Rama. 2007. Analisis Sistem Perawatan Komponen Bearing Bottop Roller dan V belt mesin Ring Frame RY-5 pada Departemen Spinning II (di PT Danliris Surakarta). Jurnal Teknik Industri. Vol 2(2), pp 40-48.

Rinawati, Dyah Ika. Dewi, Nadia Cynthia 2014. Analisis Penerapan Total Productive Maintenance (TPM) Menggunakan Overall Equipment Efectiveness (OEE) Dan Six big losses Pada Mesin Cavitec Di PT. Essentra Surabaya. Pros iding SNATIF Ke -1 Tahun 201 4. ISBN: 978-602-1180-04-4.

Sudrajat, A., 2011. Pedoman Praktis Manajemen Perawatan Mesin Industri. Refika Aditama. Bandung. 